\title{
Microbiological Efficacy of a New Ophthalmic Formulation of Moxifloxacin Dosed Twice-Daily for Bacterial Conjunctivitis
}

Shachar Tauber · Gale Cupp · Richard Garber · John Bartell · Firoz Vohra · David Stroman

Received: April 15, 2011 / Published online: June 14, 2011

(C) The Author(s) 2011. This article is published with open access at Springerlink.com

\section{ABSTRACT}

Introduction: An alternative formulation of $0.5 \%$ moxifloxacin ophthalmic solution $\left(\right.$ Moxeza $^{\circledR}$, MOXI-AF, Alcon Laboratories, Inc., Fort Worth, TX, USA) containing xanthan gum to prolong retention on the eye has been developed. MOXI-AF was designed to optimize the treatment regimen for bacterial conjunctivitis for the convenience of the patient with twice-daily dosing. Methods: A safety and efficacy clinical study was conducted as a multicenter, vehiclecontrolled, randomized, double-masked, parallel group study in clinically diagnosed bacterial conjunctivitis patients aged $>28$ days. MOXI-AF or its vehicle was dosed one drop twice-daily for 3 days. Microbiological specimens were obtained from affected eyes on day 1 , prior to the initial dose, and on day 4 after 3 days of dosing, and

Shachar Tauber

St. John's Clinic - Eye Specialists, Springfield, MO, USA

Gale Cupp · Richard Garber · John Bartell · Firoz Vohra • David Stroman $(\triangle)$

Alcon Research, Ltd., 6201 South Freeway, Fort Worth, TX, 76134, USA. E-mail: David.Stroman@AlconLabs.com processed using routine clinical microbiology laboratory methods. All recovered bacteria were identified to the species level. Results: This paper reports on the microbiological success rate, a secondary efficacy variable in the trial. All patients (1180) were randomized to treatment. Patient age ranged from 30 days to 92 years. The microbiological success rate for patients treated topically with MOXI-AF twice-daily for 3 days was $74.5 \%$, compared with $56.0 \%$ of patients treated with its vehicle control $(P<0.0001)$. MOXI-AF was also statistically more effective than vehicle in eradicating the three principle conjunctivitis pathogens, Haemophilus influenzae (98.5\% vs. 59.6\%, respectively), Streptococcus pneumoniae (86.4\% vs. $50.0 \%$, respectively), and Staphylococcus aureus (94.1\% vs. $80.0 \%$, respectively) $(P<0.001)$. Conclusion: The xanthan gum-based $0.5 \%$ moxifloxacin ophthalmic formulation, MOXI-AF, provides effective eradication of the three principle causative pathogens of bacterial conjunctivitis across all age groups when dosed twice-daily for 3 days.

Keywords: bacterial conjunctivitis; fluoroquinolone; microbial efficacy; moxifloxacin; ophthalmic solution 


\section{INTRODUCTION}

The most common ocular infection seen by general practitioners is bacterial conjunctivitis. ${ }^{1}$ It is highly contagious and often transferred to the other eye or to another individual by contact. More than half of all red eye cases in young children can be attributed to bacterial pathogens, ${ }^{2}$ the most common being Haemophilus influenzae and Streptococcus pneumoniae.

Moxifloxacin hydrochloride is a fourth generation fluoroquinolone developed as tablet and intravenous formulations (AVELOX ${ }^{\circledR}$, Bayer-Schering Pharma AG, Berlin, Germany) for the treatment of various infections, including community-acquired pneumonia, acute exacerbation of chronic bronchitis, acute sinusitis, and uncomplicated skin and skin structure infections. In 2003, a topical ophthalmic formulation of moxifloxacin, VIGAMOX $^{\circledR}$ (moxifloxacin hydrochloride ophthalmic solution $0.5 \%$ as base, Alcon Laboratories, Inc., Fort Worth, TX, USA), was approved, and is marketed for the treatment of bacterial conjunctivitis in the US. The approved dosage and administration for VIGAMOX is one drop in the affected eye 3 times a day (TID) for 7 days.

An alternative formulation of $0.5 \%$ moxifloxacin ophthalmic solution $\left(\mathrm{Moxeza}^{\circledR}\right.$, MOXI-AF, Alcon Laboratories, Inc., Fort Worth, TX, USA) containing xanthan gum to prolong retention on the eye has been developed. MOXI-AF was designed to improve the treatment regime of bacterial conjunctivitis for the convenience of the patient by reducing the dosing frequency compared with VIGAMOX (twice-daily [BID] versus TID). This is the first report of results from a phase 3 clinical trial designed to demonstrate the safety and efficacy of MOXI-AF for the treatment of bacterial conjunctivitis. This paper reports on the microbiological success rate, a secondary efficacy variable of the clinical study.

\section{METHODS}

\section{Study Design}

This clinical study was designed as a multicenter, vehicle-controlled, randomized, double-masked, parallel group study (NCT00759148) conducted in accordance with Good Clinical Practices, the Declaration of Helsinki, and Health Insurance Portability and Accountability Act (HIPAA) guidelines. All study sites received approval from their respective institutional review boards or independent ethics committees. Prior to performing any study screening procedures, every patient or legally authorized representative (ie, parent or guardian) provided signed informed consent.

\section{Patients}

Patients were $>28$ days old and had a clinical diagnosis of bacterial conjunctivitis in one or both eyes based on bulbar conjunctival injection and discharge (minimum score of 1 on a 4-point scale for each sign) and matting. Patient eligibility was independent of a positive bacterial culture at day 1. Patients were excluded from the study if signs and symptoms of bacterial conjunctivitis had begun longer than 4 days prior to the first visit.

\section{Treatment}

Eligible patients were randomized in a 1:1 ratio to treatment with MOXI-AF or vehicle. To maintain masking, specifically designated site personnel other than the study investigator instilled the first dose of medication at the day 1 visit. Patients received one drop of MOXI-AF or 
vehicle in the conjunctival sac of both eyes BID (morning and evening) for 3 days (a total of six drops per eye). Patients were evaluated clinically at three scheduled visits: day 1 (screening/ baseline), day 3, and day 4 (end of therapy visit). The last visit took place 12-48 hours after administration of the last dose.

\section{Microbiological Specimens - Collection and Processing}

Two microbiology swab specimens, the first swab for recovery of bacteria isolates and the second for polymerase chain reaction (PCR) detection of adenovirus and Chlamydia, were collected from patients' affected eyes before administration of the study medication at day 1. Microbiological specimens were also collected on day 4 , after 3 days of therapy or at any time a patient was declared a treatment failure by the investigator.

Microbiological specimens were shipped overnight to a central laboratory (Eurofins Medinet, Inc., Chantilly, VA, USA) and were processed within 24-72 hours of collection. For the first swab, standard microbiology methods were used for recovery and purification of bacterial isolates. Characterization of each bacterial isolate to the species and strain level included, as appropriate, both phenotypic testing (Gram staining, VITEK ${ }^{\circledR}$ AutoMicrobic System, bioMérieux, Inc., Durham, NC, USA, or $\mathrm{API}^{\circledR}$ biochemical test strips, bioMérieux, Inc., Durham, NC, USA) and genotypic methods (RiboPrinter ${ }^{\circledR}$ Microbial Characterization System, DuPont Qualicon, Wilmington, DE, USA, and/ or sequence analysis of the $16 \mathrm{~S}$ rRNA gene using MicroSeq ${ }^{\circledR}$ software and reagents, Applied Biosystems, Carlsbad, CA, USA).

Actual recovery methodology was not used for adenovirus and Chlamydia spp. Instead, total DNA was extracted from the second swab specimen using the QIAamp ${ }^{\circledR}$ DNA Mini
Kit (Qiagen, Valencia, CA, USA). PCR was subsequently performed on these DNA extracts to detect either adenovirus or Chlamydia.

\section{Analysis of the Microbiological Variables}

The intent-to-treat (ITT) dataset includes all randomized patients who received treatment. Only those ITT patients from whose affected eye(s) bacteria were recovered on day 1 were included in the microbiological intent-to-treat (MBITT) dataset. The modified per protocol (MPP) dataset included only those MBITT patients who finished the study; that is, completed an exit visit and complied with all conditions of the study protocol.

\section{Microbiological Efficacy by Patient}

The patient level microbiological efficacy outcome was based on the response of one eye, the "worst eye" or "study eye" on day 1 . In the case that both eyes were affected and the clinical signs and symptoms were the same, the right eye was chosen as the "study eye" for analysis. A patient was declared a microbiological success if all pretherapy bacterial isolate(s) recovered were eradicated from the "study eye" specimen at the day 4 exit visit. A patient was declared a microbiological failure if: a) any of the day 1 bacterial strains were recovered from the "study eye" specimen at the day 4 exit visit; b) bacterial strains were recovered from the "study eye" at an exit specimen from a patient with unresolved clinical signs or symptoms.

\section{Microbiological Eradication by Species}

Another measure of effectiveness of the therapy is to examine the ability of the therapy to eradicate specific bacterial species in conjunctivitis. The bacterial species eradication 
rate was calculated by dividing the number of eradicated isolates of a particular species by the total number of isolates of that species (eradicated plus persisting isolates), multiplied by 100 . For purposes of this calculation, eradicated isolates in the "study eye" of a patient declared as a microbiological failure were not counted because of the clinical failure.

\section{RESULTS}

\section{Study Population}

The overall study population demographics are presented in Table 1. Patients ranged in age from 30 days to 92 years. For all demographic categories, the distribution of patients in the two treatment arms was comparable. A total of 1180 patients were enrolled and randomized in the study from October 2008 to March 2010 from 82 investigational sites and 27 states across the United States. There were 1179 evaluable patients in the ITT dataset and 847 evaluable patients in the MBITT dataset, 424 treated with MOXI-AF and 423 treated with vehicle. There were 769 evaluable patients in the MPP dataset, 385 treated with MOXI-AF and 384 treated with vehicle.

\section{Microbiological Efficacy by Patient}

The microbiological efficacy success rate is presented in Table 2. In the MBITT dataset, $74.5 \%$ of the patients treated BID for 3 days with MOXI-AF were microbiological successes, compared with $56.0 \%$ for patients treated with vehicle $(P<0.0001)$.

\section{Microbiological Eradication by Species}

The eradication rate for each of the three principle bacterial conjunctivitis pathogens (H. influenzae, S. pneumoniae, and Staphylococcus aureus) for both the MBITT and MPP data sets is presented in Table 3. H. influenzae and $S$. pneumoniae are also recognized as major respiratory pathogens. MOXI-AF was significantly more effective than vehicle in eradicating the three principle conjunctivitis pathogens, $H$. influenzae $(98.5 \%$ vs. $59.6 \%$, respectively), $S$. pneumoniae ( $86.4 \%$ vs. $50.0 \%$, respectively), and $S$. aureus (94.1\% vs. $80.0 \%$, respectively) $(P<0.001)$.

In Table 4 , the frequency of occurrence of the three principle pathogens as a function of

Table 1. Patient demographics at baseline.

\begin{tabular}{|c|c|c|}
\hline & \multicolumn{2}{|c|}{ Overall study population } \\
\hline & MOXI-AF & Vehicle \\
\hline Patients, $n$ & 593 & 586 \\
\hline \multicolumn{3}{|l|}{ Age, $n(\%)^{*}$} \\
\hline 28 days- 23 months & $49(8.3)$ & $47(8.0)$ \\
\hline $2-11$ years & $174(29.3)$ & $184(31.4)$ \\
\hline $12-17$ years & $71(12.0)$ & $72(12.3)$ \\
\hline 18-64 years & $257(43.3)$ & $230(39.2)$ \\
\hline$\geq 65$ years & $42(7.1)$ & $53(9.0)$ \\
\hline \multicolumn{3}{|l|}{ Sex, $n(\%)$} \\
\hline Male & $240(40.5)$ & $248(42.3)$ \\
\hline Female & $353(59.5)$ & $338(57.7)$ \\
\hline \multicolumn{3}{|l|}{ Race, $n(\%)$} \\
\hline White & $463(78.1)$ & $488(83.3)$ \\
\hline Black or African & $84(14.2)$ & $55(9.4)$ \\
\hline \multicolumn{3}{|l|}{ American } \\
\hline Asian & $18(3.0)$ & $8(1.4)$ \\
\hline Native Hawaiian & $3(0.5)$ & $1(0.2)$ \\
\hline American Indian & $6(1.0)$ & $6(1.0)$ \\
\hline Other & $14(2.4)$ & $21(3.6)$ \\
\hline Multiracial & $5(0.8)$ & $7(1.2)$ \\
\hline \multicolumn{3}{|l|}{ Ethnicity, $n(\%)$} \\
\hline $\begin{array}{l}\text { Hispanic, Latino or } \\
\text { Spanish }\end{array}$ & $141(23.8)$ & $152(25.9)$ \\
\hline $\begin{array}{l}\text { Not Hispanic, Latino } \\
\text { or Spanish }\end{array}$ & $452(76.2)$ & $434(74.1)$ \\
\hline
\end{tabular}

*Actual age range: 30 days-92 years 
Table 2. Patient microbiological success at day 4 .

\begin{tabular}{lcccccccc}
\hline & \multicolumn{3}{c}{ MOXI-AF } & & \multicolumn{3}{c}{ Vehicle } \\
\cline { 2 - 3 } & Total & Yes & & & Total & Yes & \\
& $n$ & $n$ & & & $n$ & $n$ & $\%$ & P value \\
\hline MBITT & 424 & 316 & 74.5 & & 423 & 237 & 56.0 & $<0.0001$ \\
MPP & 385 & 285 & 74.0 & & 384 & 220 & 57.3 & $<0.0001$ \\
\hline
\end{tabular}

MBITT $=$ microbiological intent-to-treat population; $\mathrm{MPP}=$ modified per protocol population .

Table 3. Eradication rate by species at day 4 .

\begin{tabular}{|c|c|c|c|c|c|c|}
\hline & \multicolumn{3}{|c|}{ MOXI-AF } & \multicolumn{3}{|c|}{ Vehicle } \\
\hline & Total & Yes & & Total & Yes & \\
\hline & $n$ & $n$ & $\%$ eradicated & $n$ & $n$ & $\%$ eradicated \\
\hline \multicolumn{7}{|l|}{ MBITT } \\
\hline H. influenzae & 67 & 66 & 98.5 & 52 & 31 & 59.6 \\
\hline S. pneumoniae & 22 & 19 & 86.4 & 18 & 9 & 50.0 \\
\hline S. aureus & 17 & 16 & 94.1 & 15 & 12 & 80.0 \\
\hline \multicolumn{7}{|l|}{ MPP } \\
\hline H. influenzae & 60 & 60 & 100 & 47 & 29 & 61.7 \\
\hline S. pneumoniae & 18 & 16 & 88.9 & 14 & 8 & 57.1 \\
\hline S. aureus & 16 & 15 & 93.8 & 14 & 11 & 78.6 \\
\hline
\end{tabular}

MBITT $=$ microbiological intent-to-treat population; $\mathrm{MPP}=$ modified per protocol population

Table 4. Distribution of patients by age and recovered pretherapy bacterial species.

\begin{tabular}{|c|c|c|c|c|c|c|}
\hline & & 28 days- & & & & \\
\hline & $\begin{array}{l}\text { Total patients } \\
\qquad(n=847)\end{array}$ & $\begin{array}{c}23 \text { months } \\
\quad(n=87)\end{array}$ & $\begin{array}{c}2-11 \text { years } \\
(n=263)\end{array}$ & $\begin{array}{c}12-17 \text { years } \\
(n=88)\end{array}$ & $\begin{array}{c}18-64 \text { years } \\
(n=334)\end{array}$ & $\begin{array}{c}\geq 65 \text { years } \\
(n=75)\end{array}$ \\
\hline H. influenzae & $177(20.9 \%)$ & $48(55.2 \%)$ & $92(35.0 \%)$ & $4(4.5 \%)$ & $28(8.4 \%)$ & $5(6.7 \%)$ \\
\hline S. pneumoniae & $74(8.7 \%)$ & $14(16.1 \%)$ & $32(12.2 \%)$ & $7(8.0 \%)$ & $17(5.1 \%)$ & $4(5.3 \%)$ \\
\hline S. aureus & 67 (7.9\%) & $2(2.3 \%)$ & $22(8.4 \%)$ & $4(4.5 \%)$ & $22(6.6 \%)$ & $17(22.7 \%)$ \\
\hline
\end{tabular}

patient age is presented. These bacterial species were not recovered equally among conjunctivitis patients of various age groups. $H$. influenzae and $S$. pneumoniae infections were more common in younger patients ( $<12$ years of age). $S$. aureus was recovered from one in four patients who were $\geq 65$ years of age, which is approximately three times the frequency of other age groups. Considering the number of patients affected for each age group, combined with the eradication rate for these three species, MOXI-AF was shown to be equally active across all age groups.

\section{Microbiology of Conjunctivitis}

A total of 1700 bacterial isolates were recovered from the affected eyes of 1180 patients prior to the initiation of therapy. 
Table 5. Bacteria recovered from conjunctivitis patients.

\begin{tabular}{|c|c|c|}
\hline & MOXI-AF & Vehicle \\
\hline Total isolates $(n=1305)$ & 646 & 659 \\
\hline Gram-positive bacteria, $n(\%)$ & $536(83 \%)$ & $540(82 \%)$ \\
\hline \multicolumn{3}{|l|}{ Actinomycetaceae } \\
\hline Actinomyces meyeri & 1 & 0 \\
\hline \multicolumn{3}{|l|}{ Aerococcaceae } \\
\hline Aerococcus viridans & 1 & 0 \\
\hline \multicolumn{3}{|l|}{ Bacillaceae } \\
\hline Bacillus cereus & 1 & 1 \\
\hline Bacillus circulans & 0 & 2 \\
\hline Bacillus licheniformis & 1 & 1 \\
\hline Bacillus megaterium & 1 & 0 \\
\hline Bacillus mycoides & 1 & 0 \\
\hline Bacillus niacini & 1 & 0 \\
\hline Bacillus pumilus & 3 & 4 \\
\hline Bacillus species & 2 & 0 \\
\hline Bacillus subtilis & 1 & 1 \\
\hline Bacillus thuringiensis & 1 & 0 \\
\hline \multicolumn{3}{|l|}{ Carnobacteriaceae } \\
\hline Granulicatella species & 0 & 1 \\
\hline \multicolumn{3}{|l|}{ Corynebacteriaceae } \\
\hline Corynebacterium & 1 & 1 \\
\hline \multicolumn{3}{|l|}{ amycolatum } \\
\hline Corynebacterium bovis & 0 & 1 \\
\hline Corynebacterium & 1 & 0 \\
\hline \multicolumn{3}{|l|}{ kroppenstedtii } \\
\hline Corynebacterium macginleyi & 8 & 6 \\
\hline Corynebacterium & 1 & 0 \\
\hline \multicolumn{3}{|l|}{ propinquum } \\
\hline Corynebacterium & 0 & 2 \\
\hline \multicolumn{3}{|l|}{ pseudodiphtheriticum } \\
\hline Corynebacterium species & 0 & 3 \\
\hline Corynebacterium striatum & 0 & 1 \\
\hline \multicolumn{3}{|l|}{ Enterococcaceae } \\
\hline Enterococcus casseliflavus & 0 & 1 \\
\hline Enterococcus faecalis & 5 & 5 \\
\hline Enterococcus faecium & 0 & 1 \\
\hline Enterococcus species & 0 & 1 \\
\hline \multicolumn{3}{|l|}{ Microbacteriaceae } \\
\hline Microbacterium oxydans & 1 & 0 \\
\hline \multicolumn{3}{|l|}{ Micrococcaceae } \\
\hline Kocuria rhizophila & 1 & 0 \\
\hline
\end{tabular}

\begin{tabular}{|c|c|c|}
\hline & MOXI-AF & Vehicle \\
\hline Total isolates $(n=1305)$ & 646 & 659 \\
\hline Gram-positive bacteria, $n(\%)$ & $536(83 \%)$ & $540(82 \%)$ \\
\hline Rothia dentocariosa & 1 & 0 \\
\hline Rothia mucilaginosa & 2 & 1 \\
\hline \multicolumn{3}{|l|}{ Norcardiaceae } \\
\hline Rhodococcus species & 1 & 0 \\
\hline \multicolumn{3}{|l|}{ Paenibacillaceae } \\
\hline Brevibacillus borstelensis & 0 & 3 \\
\hline Brevibacillus laterosporus & 0 & 1 \\
\hline Paenibacillus species & 1 & 1 \\
\hline \multicolumn{3}{|l|}{ Propionibacteriaceae } \\
\hline Propionibacterium acnes & 193 & 187 \\
\hline Propionibacterium & 0 & 1 \\
\hline granulosum & & \\
\hline Propionibacterium species & 5 & 3 \\
\hline \multicolumn{3}{|l|}{ Staphylococcaceae } \\
\hline Dolosigranulum pigrum & 1 & 1 \\
\hline Staphylococcus aureus & 31 & 27 \\
\hline Staphylococcus capitis & 39 & 48 \\
\hline Staphylococcus caprae & 1 & 1 \\
\hline Staphylococcus epidermidis & 142 & 140 \\
\hline Staphylococcus hemolyticus & 1 & 0 \\
\hline Staphylococcus hominis & 5 & 5 \\
\hline Staphylococcus pasteuri & 1 & 1 \\
\hline Staphylococcus piscifermentans & 1 & 0 \\
\hline Staphylococcus saprophyticus & 3 & 0 \\
\hline Staphylococcus warneri & 5 & 8 \\
\hline \multicolumn{3}{|l|}{ Streptococcaceae } \\
\hline Lactococcus lactis & 1 & 2 \\
\hline Streptococcus cristatus & 1 & 2 \\
\hline Streptococcus gordonii & 2 & 0 \\
\hline Streptococcus mitis & 17 & 16 \\
\hline Streptococcus oralis & 1 & 5 \\
\hline Streptococcus parasanguinis & 4 & 2 \\
\hline Streptococcus pneumoniae & 35 & 33 \\
\hline Streptococcus salivarius & 1 & 3 \\
\hline Streptococcus sanguis & 2 & 2 \\
\hline Streptococcus species & 4 & 9 \\
\hline Streptococcus viridans group & 3 & 6 \\
\hline
\end{tabular}




\begin{tabular}{lcc}
\hline & MOXI-AF & Vehicle \\
\cline { 2 - 3 } Total isolates $(\mathbf{n}=\mathbf{1 3 0 5})$ & $\mathbf{6 4 6}$ & $\mathbf{6 5 9}$ \\
\hline Gram-negative bacteria, $n$ (\%) & $\mathbf{1 1 0}(\mathbf{1 7 \%})$ & $\mathbf{1 1 9}(\mathbf{1 8 \%})$ \\
\hline Comamonadaceae & & \\
Acidovorax temperans & 3 & 1 \\
\hline Enterobacteriaceae & & \\
Citrobacter koseri & 1 & 0 \\
Enterobacter aerogenes & 0 & 1 \\
Enterobacter cloacae & 1 & 0 \\
Enterobacter hormaechei & 1 & 2 \\
Enterobacter species & 0 & 2 \\
Escherichia coli & 2 & 1 \\
Klebsiella oxytoca & 0 & 1 \\
Klebsiella ozaenae & 0 & 1 \\
Klebsiella pneumoniae & 1 & 4 \\
Pantoea species & 0 & 2 \\
Proteus mirabilis & 1 & 4 \\
Proteus vulgaris & 1 & 0 \\
Raoultella ornithinolytica & 0 & 1 \\
Serratia marcescens & 4 & \\
\hline Flavobacteriaceae & & \\
Chryseobacterium indologenes & 3 & \\
Elizabethkingia miricola & 1 & \\
Terrimonas species & 0 & \\
\hline & & \\
\hline
\end{tabular}

A total of 1305 isolates were recovered from 847 study eyes (MBITT dataset) used for analysis. As shown in Table 5, 82\% (1076/1305) of the isolates belonged to 58 Gram-positive species (17 genera) and 18\% (229/1305) of the isolates belonged to 31 Gram-negative species (19 genera) and the distribution of bacterial species was similar between the two treatment groups. In addition, adenovirus was detected in 15 of the 1180 patients, while Chlamydia was not detected in any patient.

\section{DISCUSSION}

Bacterial conjunctivitis is usually selflimiting, with resolution after approximately

\begin{tabular}{lcc}
\hline & MOXI-AF & Vehicle \\
\cline { 2 - 3 } Total isolates (n=1305) & $\mathbf{6 4 6}$ & $\mathbf{6 5 9}$ \\
\hline Gram-negative bacteria, $\boldsymbol{n}$ (\%) & $\mathbf{1 1 0}(\mathbf{1 7 \%})$ & $\mathbf{1 1 9}(\mathbf{1 8 \%})$ \\
\hline Moraxellaceae & & \\
Acinetobacter baumannii & 0 & 1 \\
Acinetobacter genospecies 3 & 0 & 1 \\
Acinetobacter species & 1 & 0 \\
Acinetobacter ursingii & 1 & 0 \\
Moraxella catarrhalis & 1 & 2 \\
Moraxella lacunata & 0 & 2 \\
\hline Neisseriaceae & & \\
Neisseria meningitidis & 0 & 1 \\
\hline Pasteurellaceae & & \\
Haemophilus influenzae & 82 & 84 \\
\hline Pseudomonadaceae & & \\
Pseudomonas aeruginosa & 2 & 2 \\
Pseudomonas species & 1 & 0 \\
\hline Sphingomonadaceae & & \\
Sphingomonas species & 0 & 1 \\
Sphingomonas yanoikuyae & 0 & \\
\hline Xanthomonadaceae & & \\
Stenotrophomonas & 3 & \\
maltophilia & & \\
\hline & & \\
\hline
\end{tabular}

10 days, and rarely lasting longer than 3 weeks. Treatment is usually empiric using an antibiotic with broad coverage for the wide variety of conjunctivitis pathogens. Prompt, appropriate treatment reduces the time to disease resolution, minimizes the risk of sequelae, helps prevent the spread of infection, and reduces the time away from work or school. ${ }^{3-9} \mathrm{~A}$ Cochrane analysis of placebo-controlled clinical trials with broadspectrum topical antibiotics demonstrated the benefit of treatment in improving clinical and microbiological remission rates after 2 to 5 days of treatment, and these advantages persisted, although reduced, through days 6 to 10 of therapy. ${ }^{10}$ 
In this large multicenter study with investigators spread across the United States, the isolates recovered prior to the initiation of therapy provide a comprehensive picture of the diverse nature of microorganisms that can be associated with bacterial conjunctivitis. The spectrum of bacteria recovered is considered typical for bacterial conjunctivitis patients. ${ }^{11,12}$

Most topical ophthalmic antibiotic products approved in the United States for the treatment of bacterial conjunctivitis have a 7- to 10-day treatment regimen, totaling a minimum of 21-42 or more drops over a course of therapy. A full course of therapy with MOXI-AF is 14 drops over 7 days. Results from this study demonstrate that MOXI-AF, when dosed topically BID for 3 days (total six drops per eye), was statistically superior to its vehicle in the percentage of patients classified as microbiological successes after 3 days of treatment ( $75 \%$ vs. $56 \%, P<0.0001)$. MOXI-AF was also significantly more effective than its vehicle in eradicating the three principle conjunctivitis pathogens. The eradication rate of $H$. influenzae was $98.5 \%$ for MOXI-AF versus $59.6 \%$ for its vehicle; S. pneumoniae was $86.4 \%$ for MOXI-AF compared with $50.0 \%$ for vehicle, and $S$. aureus was $94.1 \%$ for MOXI-AF compared with $80.0 \%$ for vehicle.

\section{CONCLUSION}

These microbiological eradication data demonstrated that MOXI-AF provided effective eradication of bacterial pathogens following 3 days of treatment for bacterial conjunctivitis. The convenience of the simplified BID dosing regimen and the rapid eradication of the most common causative pathogens may be expected to allow earlier return to daycare or school for children as young as 1 month old, without risk of spreading the infection to others.

\section{ACKNOWLEDGMENTS}

This clinical study was funded by Alcon Research, Ltd. Financial support for this publication was provided by Alcon Research, Ltd. (Fort Worth, TX, USA). Writing and editorial assistance was provided by Heather A. Edens, PhD, H EDENS, LLC, Marietta, GA, USA.

The authors thank participating investigators that enrolled patients in this study: Dr. Wilson Andrews, Jr., Dr. Jason Bacharach, Dr. Russel Bain, Dr. James Bean, Dr. William Beck, Dr. Peter Berkowitz, Dr. John V. Bernard, Dr. Mark Bibler, Dr. Maria Blahey, Dr. James D. Branch, Dr. John Calcagno, Dr. Steve Choi, Dr. Andrew Cottingham, Dr. Lawrence Curry, Dr. David Damian, Dr. Jung Dao, Dr. Peter Dawson, Dr. Mark Dorfman, Dr. Corey Ericksen, Dr. William Faulkner, Dr. Brian Feaver, Dr. William Flynn, Dr. Fred George, Dr. Joseph Gira, Dr. Damien Goldberg, Dr. Carlos Gonzales, Dr. Judith Grossberg, Dr. Piyush Gupta, Dr. Laurie Harris-Ford, Dr. Richard Hector, Dr. David Hillman, Dr. Jeffrey Hirschfield, Dr. William Hitchcock, Dr. Claudia Hudson, Dr. Wade D. Huffman, Dr. Frank Hughes, Dr. Michael Jacobs, Dr. Barry Katzman, Dr. Thomas F. Kelly, Dr. Sherif Khamis, Dr. Sukhdev Khurma, Dr. Stanley Koch, Dr. Stephen Lane, Dr. Christopher Lin, Dr. Larry Lothringer, Dr. Gary Luffey, Dr. Ranjan Malhotra, Dr. Frank Mazzone, Dr. Tracey McGuinn, Dr. Eugene McLaurin, Dr. Edward J. Meier, Dr. Andrew Moyes, Dr. Julie Mullen, Dr. Robert Pendleton, Dr. Patti Perry, Dr. Scott Petermann, Dr. John Pullman, Dr. Paul Qaqundah, Dr. Sanjay Rao, Dr. Peter Rees, Dr. Howard Schenker, Dr. Shelly Senders, Dr. Grady Shaw, Dr. Phillip Lee Shettle, Dr. Steven Silverstein, Dr. Christopher Smith, Dr. Richard Stanford, Dr. Emil Stein, Dr. Jeffrey Stewart, Dr. Timothy Sullivan, Dr. Mikio Tachibana, Dr. Shachar Tauber, Dr. Rolando Toyos, Dr. Clark Tsai, Dr. Jay Wallshein, Dr. Francis Wapner, Dr. Jeffrey Wasserstrom, and Dr. Paul Wisman. 
The trial registration number is: NCT00759148.

Shachar Tauber is a consultant for Allergan, Inc., Ista Pharmaceuticals, and Inspire Pharmaceuticals, and a founder and owner of Ocugenics which has received funding from the U.S. Department of Defense. Shachar Tauber's wife is an employee of Alcon Laboratories, Inc. Gale Cupp, Richard Garber, Firoz Vohra, John Bartell and David Stroman are employees of Alcon Research, Ltd. Alcon Research, Ltd. designed the study and performed the data analysis. Together with study investigators, Alcon participated in collection and interpretation of data, in the writing of the manuscript, and in the decision to submit the manuscript for publication.

David Stroman is the guarantor for this article, and takes responsibility for the integrity of the work as a whole.

Open Access. This article is distributed under the terms of the Creative Commons Attribution Noncommercial License which permits any noncommercial use, distribution, and reproduction in any medium, provided the original author(s) and source are credited.

\section{REFERENCES}

1. Drancourt M, Herbert L. Conjunctivitis, keratitis and infections of periorbital structures. In: Cohen J, Powderly WG, Opal SM, eds. Cohen \& Powderly: Infectious Diseases. 3 ed. Mosby, an Imprint of Elsevier, Inc.; 2010.
2. Buznach N, Dagan R, Greenberg D. Clinical and bacterial characteristics of acute bacterial conjunctivitis in children in the antibiotic resistance era. Pediatr Infect Dis J. 2005;24:823-828.

3. Ohnsman CM. Exclusion of students with conjunctivitis from school: policies of state departments of health. J Pediatr Ophthalmol Strabismus. 2007;44:101-5.

4. Lichtenstein SJ, Dorfman M, Kennedy R, Stroman D. Controlling contagious bacterial conjunctivitis. J Pediatr Ophthalmol Strabismus. 2006;43:19-26.

5. CDC. Outbreak of bacterial conjunctivitis at a college - New Hampshire, January-March, 2002. MMWR Morb Mortal Wkly Rep. 2002;51:205-207.

6. CDC. Pneumococcal conjunctivitis at an elementary school - Maine, September 20-December 6, 2002. MMWR Morb Mortal Wkly Rep. 2002;52:64-66.

7. Martin M, Turco JH, Zegans ME, et al. An outbreak of conjunctivitis due to atypical Streptococcus pneumoniae. N Engl J Med. 2003;348:1112-1121.

8. D'Arienzo PA, Wagner RS, Jamison T, Bell B, Dajcs JJ, Stroman DW. Comparison of fluoroquinolone kinetics of kill in susceptible and resistant gram-positive conjunctival pathogens. Adv Ther 2010;27:39-47.

9. Wagner RS, Granet DB, Lichtenstein SJ, et al. Kinetics of kill of bacterial conjunctivitis isolates with moxifloxacin, a fluoroquinolone, compared with the aminoglycosides tobramycin and gentamicin. Clin Ophthalmol. 2010;4:41-45.

10. Sheikh A, Hurwitz B. Antibiotics versus placebo for acute bacterial conjunctivitis. Cochrane Database Syst Rev 2006;CD001211.

11. Stroman DW, Dajcs JJ, Cupp GA, Schlech BA. In vitro and in vivo potency of moxifloxacin and moxifloxacin ophthalmic solution $0.5 \%$, a new topical fluoroquinolone. Surv Ophthalmol. 2005;50(Suppl. 1):S16-S31.

12. Hovding G. Acute bacterial conjunctivitis. Acta Ophthalmol 2008;86:5-17. 